\title{
Ethical Challenges Faced by Senior Dental Students and General Dentists
}

\author{
Fahimeh Rashidi Maybodi', Ahmad Haerian Ardakani², Mahdie Khabazzade \\ Yazdi 10 2*
}

1-Periodontics Dept, Dental Faculty, Shahid Sadoughi University of Medical Sciences, Yazd,Iran.

2-Private Practice, Yazd, Iran

\begin{tabular}{l} 
ARTICLE INFO \\
\hline Article History \\
Received:June 2021 \\
Accepted: August 2021 \\
ePublished: Oct 2021 \\
\hline Corresponding author \\
Mahdie Khabazzade \\
Yazdi,Dentist, Yazd, \\
Iran.Email: mkhabaza- \\
dehyazdi@yahoo.com
\end{tabular}

Introduction

Ethics includes the principles and values that govern individual and collective behavior under the title of right or wrong, ${ }^{(1)}$ and there is an innate tendency towards ethical values in the nature of every human being. Professional ethics is the behavior, manners, and actions of a person doing professional work. ${ }^{(2-4)}$ Medical ethics is a subgroup of professional ethics that describes the ethical and professional standards for healthcare providers ${ }^{(5)}$, and is considered as a new science by the scientific and medical societies. ${ }^{(6)}$

\begin{abstract}
Background and Aim: General familiarity with medical ethics sometimes does not meet the needs of dentists. The aim of this study was to evaluate the ethical entists were selected from Yazd city, Iran. A questionnaire with three doResults: The mean age of students and general dentists was $24 \pm 2$ and $30 \pm 2$ years, respectively; $42 \%$ of the respondents were males, and $58 \%$ were females. Except for one item (dentist's right to refuse treatment) $(\mathrm{P}<0.05)$, no significant difference was found between the two groups $(\mathrm{P}>0.05)$. The most common challenges faced by the participants were compromising treatment due to cost issues $(77.1 \%$ of students and $71.4 \%$ of dentists) and noticing sub-standard treatments performed by other dentists ( $64 \%$ of students and $58 \%$ of dentists). Unawareness about the way to criticize other dentists was the least commonly reported challenge ( $28 \%$ of students and $36.7 \%$ of dentists). A significant difference was found in the frequency of encountering sub-standard treatments performed by other dentists between the two groups $(\mathrm{P}=0.031)$. A significant difference in the frequency of a particular challenge between males and females was seen only in one item (disaConclusion:This study showed that dental practitioners had faced a variety of ethical challenges, that need to be addressed in dental education. However, the results of this study may not be generalizable to other cities.

Keywords: Ethics, Medical; Students, Dental; Dentists; Education
\end{abstract}

\section{J Res Dent Maxillofac Sci 2021;6(4):23-29}

Much progress has been made in dental research as well as cosmetic dentistry in the 20th century, which has brought the most important ethical problems in dentistry in the 21 st century. ${ }^{(7)}$ Since ethics has a special place in medical community, examining ethical challenges in dentistry as a branch of medical science is also important. ${ }^{(8)}$

Dental professionals and students face ethical challenges when one or more ethical rules are in conflict. 
For example, when the principle of harmlessness is confronted with autonomy under certain conditions, a real challenge arises, and there is clearly a big difference between managing everyday problems and facing ethical challenges. ${ }^{(9)}$

In clinical practice, dentists and dental students realize that it is difficult to make decisions in critical situations and adhere to ethical principles, and that a general understanding of medical ethics does not meet their needs to deal with such problems. Therefore, education of ethics should be included in dental curricula. ${ }^{(10)}$

Porter and Grey ${ }^{(11)}$ conducted a study on ethical challenges faced by dentists. They reported that poor quality of previous treatments done by the colleagues, and insurance fraud by patients were the most common challenges encountered by dentists. Kazemian et al. ${ }^{(7)}$ reported six important ethical issues in the field of dentistry as follows: inappropriate treatment procedures, not accepting liability for individual errors, overtreatment (or unnecessary treatment), inappropriate behavior with patients, non-professional discussion about another colleague's work quality, and unfair behavior towards deprived patients. ${ }^{(7)}$ In a study by Christie et al, ${ }^{(12)}$ on freshman and senior dental students on professional ethics, there were significant differences in communication skills, problem-solving ability, and honesty in behavior of senior dental students, and also their increased awareness compared with freshmen because of the received trainings.

Considering the current lack of knowledge on this topic, more attention should be paid to instruction of ethical issues for clinical practice in dental curricula ${ }^{(12)}$, practical assessment of students in the clinical setting ${ }^{(13)}$, focusing on students' ethical problems in the clinical setting ${ }^{(14)}$, revising the educational curricula to address the actual requirements of students, updating the educational content on medical ethics ${ }^{(15)}$, using personal experiences in personal and professional life, ${ }^{(16)}$ and teaching ethics along with clinical scenarios. ${ }^{(17)}$

The aim of this study was to assess the ethical challenges faced by senior dental students and general dentists in Yazd city, Iran, to prioritize these challenges in instruction of ethics in general dental curricula.

\section{Materials and Methods}

This was a descriptive, cross-sectional study. Fifty senior dental students selected by census sampling from the School of Dentistry, Shahid Sadoughi University of Medical Sciences comprised the first group. The enrolled students had passed the final two semesters of their dental education. The second group consisted of 50 general dentists working in Yazd city, Iran, who were randomly selected by using a table of random numbers. The inclusion criteria were signing informed consent forms, passing the medical ethics course by dental students and general dentists, and starting clinical practice.

Data were collected using a semi-structured questionnaire. The questionnaire consisted of three domains. The first domain included demographic information such as age and gender. The second domain included 4 hypothetical scenarios designated about ethical challenges and a single question about the main role model for ethical decisions. The third domain included three-choice questions (repeatedly, rarely, never) on overall treatment topics (sub-standard treatments done by other dentists, correction of other dentists' inappropriate treatments, disagreement over treatment decisions with other dentists, and explanation of their own treatment errors to the patient), professional behavior issues (criticizing other dentists, unnecessary over-treatment), patient-related issues (patient's request for inappropriate treatment, unrealistic expectations of the patient from the dentist), insurance issues (insurance fraud, and patients complaining about the received fee by the dentist), or some other issues (patients cannot pay the fee for service). The reliability of this questionnaire was tested by calculating the Cronbach's alpha, which was found to be 0.73 . The questionnaire used in this study has been previously validated by Porter and Grey. ${ }^{(11)}$ The Chi-square test was used to compare the frequency distribution of scores. P-values less than 0.05 were considered significant.

\section{Results}

This study evaluated 50 senior dental students with a mean age of $24 \pm 2$ years and 50 dentists with a mean age of $30 \pm 2$ years. Of all, $42 \%$ of the respondents were males and $58 \%$ were females. Also, $92 \%$ of the participants answered all the 
questions. The remaining $8 \%$ did not answer all the questions ( 8 dentists), which were replaced with new participants.

The participants' responses to the second domain of the questionnaire showed that in the first scenario regarding a patient's autonomy and treatment decision making, $91.9 \%$ of the respondents indicated the need for a detailed explanation about the treatment options provided to the patient and emphasized on the patient's role in final selection of the choice of treatment (answer choices A and B). In the second scenario, the respondents were asked about how to write an insurance report for accident compensation, and about half of the respondents $(46 \%)$ chose the answer choice D (all of the choices by explaining the probability of occurrence of each). In the third scenario regarding the dentist's reaction to the patient's inappropriate request to change the date of treatment to include it in the insurance coverage, most respondents $(67.7 \%)$ chose option B (objection to do so by explaining the legal reasons). In the abovementioned three scenarios, there were no significant differences between the frequency of choices selected by students and dentists $(\mathrm{P}>0.05)$ but the Chi-square test showed that there was a statistically significant difference between the two groups $(\mathrm{P}=0.031)$ in the frequency of answers to the fourth scenario. Of all, $66 \%$ of students and $89.8 \%$ of dentists chose answer choice A (the dentist has the right to refuse treatment). In answer to item 5 of the second part of the questionnaire (the main role model for ethical decisions), the highest frequency of responses (58.8\%) was related to option C (experienced and pioneer dentists in the field) as the main role model of participants in ethical challenges, and there was no significant difference between the two groups about this item $(\mathrm{P}=0.228$, Table 1$)$.

Table 1 presents the frequency distribution of answers to items of the second part of the questionnaire in two groups according to gender. The Chi-square test showed that no significant differences were found in the frequency distribution of responses to the items in both dentists' and students' groups in terms of gender.

The participants' responses to the third part of the questionnaire showed that the most common challenge faced by both dental students $(77.1 \%)$ and general dentists (71.4\%) was compromised treatment due to costs. Secondly, $64 \%$ of students and $58 \%$ of dentists had repeatedly encountered sub-standard treatments done by other dentists. Criticizing other dentists (topics related to professional behavior) was the least commonly reported challenge (never encountered by $28 \%$ of dental students and $36.7 \%$ of general dentists) (Table 2).

Table 2 presents the frequency of dealing with different ethical issues in the two groups. The Chi-Square test showed that there was only a statistically significant difference between the two groups about the frequency of facing non-standard treatments done by other dentists $(\mathrm{P}=0.040)$. There was only one statistically significant difference between the frequency of facing disagreement in treatment decisions with other dentists by males and females in the group of students $(\mathrm{P}=0.040)$. There was no difference between males and females in the group of dentists in any item $(\mathrm{P}>0.05)$.

\section{Discussion}

The findings of this study showed that compromised treatment due to inability of patients to pay the treatment fees $(74.2 \%)$ and sub-standard dental treatment done by other dentists (59.6\%) were among the most common ethical challenges faced by the participants. In the present study, due to limited age range of the participants, the frequency of answers to different questions was not analyzed according to age, but in the study by Porter and Grey ${ }^{(11)}$, the effect of age was significant. In a study by Bahrani et al, ${ }^{(18)}$ on the awareness of dentists about the principles of professional ethics in Shiraz, gender had no significant effect on the response of individuals; however, in the present study, it was observed that gender was effective on the responses given to one question (disagreement over treatment decisions with other dentists). This topic was not studied in the study by Bahrani et al. ${ }^{(18)}$ 
Table 1: Frequency of answers of males and females given to the items of the second domain of the questionnaire

Questions
\begin{tabular}{lrrrrr}
\hline 1- A dentist considering all alternatives, presents the patient with only one choice & $\mathbf{0 . 8 1 2}$ & Male & Female & Male & Female \\
for treatment. What is your opinion? & & & $\begin{array}{c}\text { Percentage and number of } \\
\text { responses of dental students }\end{array}$ & $\begin{array}{r}\text { Percentage and number of } \\
\text { dentists' responses }\end{array}$ \\
A) Different options should be explained to the patient and the patient should be allowed & $4(21.1 \%)$ & $4(14.3 \%)$ & $3(13.6 \%)$ & $3(12.5 \%)$ \\
to choose. & $14(73.7 \%)$ & $22(78.6 \%)$ & $16(72.7 \%)$ & $19(79.2 \%)$ \\
B) The dentist should explain the different options to the patient and guide the patient to & $1(5.3 \%)$ & $1(3.6 \%)$ & $2(9.1 \%)$ & $2(8.3 \%)$ \\
pick the right choice. & $0(0 \%)$ & $1(3.6 \%)$ & $1(4.5 \%)$ & $0(0 \%)$ \\
C) The dentist should only comment when the patient asks him to, otherwise, it is better & & & & &
\end{tabular}

to remain silent.

D) The dentist is only obliged to use his experience in a way that benefits the patients the most.

2- The dentist wants to write an insurance report for the patient who has had a minor accident and has been treated by reconstructing the chipped incisal edge of an anterior tooth. What does this report include?

A) Restoration of the incisal edge as accepted by the patient.

B) Different restorative choices (perhaps the patient will change his mind in the future)

C) Root canal treatment and prosthetic crown fabrication, although they are unlikely options.

D) All of the above by explaining the probability of occurrence of each.

3- A patient who has been visiting you for a long time for dental work has recently lost his insurance coverage and asks you to report the current cost of 500,000 Tomans for his treatment 3 weeks in advance. What is your reaction?

A) Opposition to doing so without any explanation

B) Opposition to doing so by explaining the legal reasons

C) Opposition to doing so by giving explanations other than legal reasons

D) Agreeing with the patient's request

0.434

$\begin{array}{rrrr}9(47.4 \%) & 10(35.7 \%) & 9(39.1 \%) & 11(45.8 \%) \\ 1(5.3 \%) & 4(14.3 \%) & 1(4.3 \%) & 2(8.3 \%) \\ 1(5.3 \%) & 1(3.6 \%) & 0(0 \%) & 0(0 \%) \\ 8(42.2 \%) & 12(42.9 \%) & 13(56.5 \%) & 11(45.8 \%)\end{array}$

0.449

4- A patient wants to have all his teeth pulled out, and the dentist wants to treat the teeth if they can be maintained. When the patient says that he wound find another dentist to extract his teeth, the primary dentist decides not to treat the patient. What is your opinion?

A) The dentist has the right to refuse treatment.

B) The dentist is indifferent to the patient's choice.

C) The behavior of the dentist is not logical.

D) The dentist is not economically realistic.

5- Which of the following options do you consider as your role model/reference in your ethical decisions?

0.228
A) Colleagues
B) University courses
C) Experienced and pioneer dentists in the field
D) Media

$\begin{array}{rrrr}2(10.5 \%) & 2(7.1 \%) & 3(13.6 \%) & 0(0 \%) \\ 10(52.6 \%) & 19(67.9 \%) & 14(63.6 \%) & 20(83.3 \%) \\ 2(10.5 \%) & 1(3.6 \%) & 1(4.5 \%) & 3(12.5 \%) \\ 5(26.3 \%) & 6(21.4 \%) & 4(18.2 \%) & 1(4.2 \%)\end{array}$

$0.031^{*}$

$\begin{array}{rrrr}14(73.7 \%) & 18(64.3 \%) & 18(81.8 \%) & 23(95.8 \%) \\ 2(10.5 \%) & 3(14.3 \%) & 2(9.1 \%) & 1(4.2 \%) \\ 3(15.8 \%) & 3(10.7 \%) & 1(4.5 \%) & 0(0 \%) \\ 0(0 \%) & 3(10.7 \%) & 1(4.5 \%) & 0(0 \%)\end{array}$

$\begin{array}{rrrr}0(0 \%) & 1(3.6 \%) & 2(9.1 \%) & 4(18.2 \%) \\ 6(31.6 \%) & 8(28.6 \%) & 7(31.8 \%) & 4(18.2 \%) \\ 12(63.2 \%) & 19(67.9 \%) & 11(50 \%) & 13(59.1 \%) \\ 1(5.3 \%) & 0(0 \%) & 2(9.1 \%) & 1(4.5 \%)\end{array}$


Table 2: Frequency of facing different ethical challenges in the two groups

\begin{tabular}{|c|c|c|c|c|c|c|c|c|}
\hline \multirow[t]{2}{*}{$\cdot 0 \mathbf{Z}$} & Questions & \multirow[t]{2}{*}{ P-value } & \multicolumn{3}{|c|}{ Dental students } & \multicolumn{3}{|c|}{ Dentists } \\
\hline & Issues related to treatment & & Repeatedly & Hardly & Never & Repeatedly & Hardly & Never \\
\hline 1 & $\begin{array}{l}\text { Non-standard treatment done by other } \\
\text { dentists }\end{array}$ & $0.040^{*}$ & $32(64 \%)$ & $18(36 \%)$ & $0(0 \%)$ & $29(58 \%)$ & $29(58 \%)$ & $6(12 \%)$ \\
\hline 2 & Correction of other dentists' faulty work & 0.214 & $11(22 \%)$ & $32(64 \%)$ & $7(14 \%)$ & $19(38 \%)$ & $26(52 \%)$ & $5(10 \%)$ \\
\hline 3 & $\begin{array}{l}\text { Disagreement over treatment options with } \\
\text { other dentists }\end{array}$ & 0.781 & $20(40 \%)$ & $26(52 \%)$ & $4(8 \%)$ & $19(38.8 \%)$ & $24(49 \%)$ & $6(12.2 \%)$ \\
\hline \multirow[t]{2}{*}{4} & Explain your medical errors to the patient & 0.660 & $9(18 \%)$ & $31(62 \%)$ & $10(20 \%)$ & $8(16 \%)$ & $35(70 \%)$ & $7(14 \%)$ \\
\hline & \multicolumn{8}{|l|}{ Issues related to professional work } \\
\hline 1 & Criticizing other dentists & 0.623 & $8(16 \%)$ & $28(56 \%)$ & $14(28 \%)$ & $6(12.2 \%)$ & $25(51 \%)$ & $18(36.7 \%)$ \\
\hline \multirow[t]{2}{*}{2} & Over-treatment & 0.803 & $6(12 \%)$ & $31(62 \%)$ & $13(26 \%)$ & $8(16.7 \%)$ & $28(58.3 \%)$ & $12(25 \%)$ \\
\hline & Issues related to patient & & & & & & & \\
\hline 1 & Patient asking for inappropriate treatment & 0.656 & $24(48 \%)$ & $20(40 \%)$ & $6(12 \%)$ & $24(48 \%)$ & $17(34 \%)$ & $9(18 \%)$ \\
\hline \multirow[t]{2}{*}{2} & $\begin{array}{l}\text { Unrealistic expectations of patient from } \\
\text { the dentist }\end{array}$ & 0.387 & $25(50 \%)$ & $18(36 \%)$ & $7(14 \%)$ & $29(58 \%)$ & $18(36 \%)$ & $3(6 \%)$ \\
\hline & Issues related to health insurance & & & & & & & \\
\hline 1 & Insurance fraud by patient & 0.754 & $13(26 \%)$ & $25(50 \%)$ & $12(24 \%)$ & $16(32.7 \%)$ & $16(32.7 \%)$ & $10(20.4 \%)$ \\
\hline \multirow[t]{2}{*}{2} & $\begin{array}{c}\text { Patient criticizing the dentist for the fee for } \\
\text { service }\end{array}$ & 0.170 & $22(44.9 \%)$ & $14(28.6 \%)$ & $13(26.5 \%)$ & $29(59.2 \%)$ & $14(28.6 \%)$ & $6(12.2 \%)$ \\
\hline & Other issues & & & & & & & \\
\hline 1 & Inability to pay for treatment & 0.575 & $37(77.1 \%)$ & $9(18.8 \%)$ & $2(4.2 \%)$ & $35(71.4 \%)$ & $13(26.5 \%)$ & $1(2 \%)$ \\
\hline 2 & Failure to face ethical challenges & 0.355 & $4(8 \%)$ & $37(74 \%)$ & $9(18 \%)$ & $8(17 \%)$ & $33(70.2 \%)$ & $6(12.8 \%)$ \\
\hline
\end{tabular}


$61 \%$ of dentists were aware of the principles of professional ethics regarding the rights of their patients; however, in the present study, this rate was $91.9 \%$ (the closest question of the questionnaire to the principles of professional ethics regarding patients' autonomy was question 1 in the second domain of the questionnaire). According to the answer choice A to this question, the dentist should explain different treatment options to the patient, and the patient should make the final decision regarding the choice of treatment by himself. This answer choice is more about the patients' rights than the answer choice B that is about the responsibility of dentist to fully explain the situation to the patients and help them to pick the right treatment option. In the present study, the total percentage of response to answer choices $\mathrm{A}$ and $\mathrm{B}$ was considered as awareness about the autonomy of patients.

This discrepancy was probably due to the different nature of the designated questionnaires and different interpretation of results. In a study by Tabei et al, ${ }^{(19)}$ the level of awareness of dental students about the rights of their patients was $71 \%$, which was lower than the awareness of dental students in the present study (94\%). This inconsistency is probably due to the differences in teaching of ethical topics in the two universities; as well as the differences in the questions asked in the questionnaires.

In the first scenario discussed in the second domain of the questionnaire, the patients' autonomy was examined in treatment decisions. Of all, $77.8 \%$ of the respondents believed that the patient, under the guidance and opinion of the dentist, should participate in selecting the type of treatment. However, only $14.1 \%$ of the participants chose the option that was consistent with ethical principles (the correct answer was: different options should be explained to the patient, and the patient should be allowed to pick the option that best suits his/her needs). The responses gave to this question in the present study were consistent with those reported by Porter and Grey. ${ }^{(11)}$ Also, in a study conducted by Karampourian et al, ${ }^{(20)} 83.1 \%$ of dentists believed that the patients should fully follow the dentist's opinions in choosing a treatment. It appears that ethical trainings received by dentists may have influ- enced their adherence to the principles of patient autonomy in making treatment decisions.

Regarding the second scenario, which was related to writing a report for an accident compensation claim, $44 \%$ of students and $48 \%$ of dentists selected "explaining different restorative choices to patient because perhaps the patient will change his/her mind in future". The results again, was similar to the study by porter and Grey. ${ }^{(11)}$

However, since answer choice A was more in agreement with the ethical guidelines (recontouring as accepted by patient), it seems that the question was not clear, and the participants did not understand it correctly. Otherwise, selection of answer choice $\mathrm{C}$ by the participants indicates that they selected the false unethical answer choice (root canal treatment).

In the third scenario regarding insurance fraud by patients, a higher percentage of dental students $(24 \%)$ compared with dentists $(12.2 \%)$ agreed with the unethical request of patient, which is probably due to the students' unawareness about the consequences of this action and their lower experience. Female dentists as well as female students were more likely than males to explain to the patients the legal reasons for their opposition to do so, but these differences were not statistically significant, and these results were consistent with those of Porter and Grey. ${ }^{(1)}$

The fourth scenario evaluated the dentist's right to refuse treatment. The majority of participants in both groups pointed to the dentist's right to refuse treatment, which was consistent with the study by Porter and Grey. ${ }^{(11)}$

But in the present study, the frequency of dentists who refused to treat the patients was more than students $(66 \%)$, and this difference was statistically significant $(\mathrm{P}<0.05)$. This finding could be due to the greater clinical experience of dentists. In the study by Karampourian et al [20], 19 dentists $(63.7 \%)$ believed that dentists do not have the responsibility to accept all types of patients with different conditions and characteristics.

The fifth item showed that most general dentists $(51.1 \%)$ and students $(66 \%)$ chose experienced and pioneer dentists as their role models. In the study by Kazemian et al, ${ }^{(7)}$ most participants believed that their colleagues could be their role models in ethical issues. Also, in the study by 
Karampourian et al, [20] all participants believed that they should provide their experiences with ethical issues to their colleagues. In the study by Porter and Grey, ${ }^{(11)}$ experiences of other dentists were the most common source for ethical decision making.

In the present study, the frequency of repeated encounter with ethical challenges was also asked from senior dental students and general dentists in Yazd in 2019. The rate of students' repeated encounters with non-standard treatments done by other dentists was significantly higher than dentists $(\mathrm{P}=0.04)$, which was consistent with the findings of Porter and Grey. ${ }^{(11)}$ This could be due to the fact that dentists are more cautious about commenting on a work done by their colleagues. This challenge would be more difficult if the patient directly asks the dentist's opinion regarding a poor treatment performed by a colleague.

Regarding professional behavior issues, in the present study, $16 \%$ of students and $12.2 \%$ of dentists reported that they repeatedly encounter situations where they do not know how to ethically criticize their colleagues. Bahrani et al. ${ }^{(18)}$ showed that $84 \%$ of dentists knew how to ethically criticize a colleague.

With regard to health insurance issues, in the present study, $44.9 \%$ of students and $59.2 \%$ of dentists reported that they were repeatedly criticized by their patients for the charged fees, which was very different from the findings of Porter and Grey $^{(11)}(3 \%)$. This difference is probably due to the differences in treatment fees. Arguing over costs after work would waste the dentist's time, disturb him/her, and question his/her credibility. To avoid this challenge, it is imperative that the dentist announces the full cost of treatment to the patients before starting the treatment. ${ }^{(18)}$ In the study by Porter and Grey, ${ }^{(11)}$ dentists repeatedly faced insurance fraud by patients, but in the present study, most of the participants reported rarely facing this challenge (48.5\%); this difference may be due to the fact that most dental procedures in Iran are not covered by insurance.

Also, in the present study, $15.5 \%$ of the participants, and in the study by Porter and Grey ${ }^{(11)}, 2 \%$ of the participants stated that they did not face any ethical challenges. This difference could be due to the people's awareness about their healthcare rights, more comprehensive professional ethics training curricula, or dentists' higher awareness of ethical principles in Australia.

Based on the results of the present study, in order to enhance the ethical knowledge of dental students who are in fact future dentists, it is suggested that the professional ethics curriculum becomes more comprehensive than before, and preferably includes the ethical challenges faced in clinical practice rather than merely focusing on theoretical topics in the field of ethics. Due to the high similarity of responses gave by senior dental students and graduate dentists, it seems that continuing education courses on the field of ethics is imperative for dentists.

\section{Conclusion}

This study showed that dentists face a variety of ethical challenges that need to be addressed in dental curricula. However, the results of this study may not be generalizable to all dental practitioners. Further similar studies with a larger sample size are required on dentists practicing in other cities.

\section{References:}

1. Borhani F, Alhani F, Mohammadi E, Abaszade A. Developing the competence of nurses' professional ethics, the necessities and challenges in teaching ethics. J Med Ethics Hist Med 2009;2(3):27-38.

2. Monafian M. Introduction to Mulla Sadra's Ethics Philosophy. J Ethics Sci Technol. 2008;2(51):744-83.

3. Bouzarjomehri F, Mansourian M, Herandi Y, Bouzarjomehri H. Academics' adherence to professional Ethics in Shahid Sadoughi University of Medical Science: Students'viewpoint. jmed. 2013; 8 (3) :44-52.

4. Khosravanian H, Shafiee M. A comparative study on the model of management in organizations with regard to western schools and Alavi teachings. PAZHUHESH NAME-E AKHLAGH 2011 [cited 2021October10];4(12):145-72. Available from: https://www.sid.ir/en/journal/ViewPaper. aspx?id $=256417$

5. Lantz MS, Bebeau MJ, Zarkowski P. The status of ethics teaching and learning in US dental schools. J Dent Educ 2011; 75(10):1295-309.

6. Ahmadi F. Relationship between professional ethics and organizational commitment. Int J Learn Dev. 2011; 1(1):178-90.

7. Kazemian A, Berg I, Finkel C, Yazdani S, Zeilhofer HF, Juergens P, Reiter-Theil S. How much dentists are ethically concerned about overtreatment; a vignette-based survey in Switzerland. BMC Medical ethics. 2015; 16(43):1-8.

8. Kazemipoor M, Keshmiri F, Owlia F, Rashidi Maybodi F. Assessment of dental residents' professionalism through 
Professionalism Mini-Evaluation Exercise (P-MEX). J Dent Educ. 2021; 85(4):456-62.

9. Kazempour Z, Ashrafi Rizi H, Taheri B. The Attention Rate of Librarians in Isfahan University of Medical Sciences and Isfahan University to Professional Ethics based on Ethical Codes of Iranian University Librarians. Health Information Management 2011; 8(6): 806.

10. Prasad DK, Hegde C, Jain A, Shetty M. Philosophy and principles of ethics: Its applications in dental practice. $\mathrm{J}$ Educ Ethics Dent. 2011; 1:2.

11. Porter SA, Grey WL. Ethical dilemmas confronting dentists in Queensland, Australia. Australian dental journal. 2002;47(3):241-8.

12. Christie CR, Bowen DM, Paarmann CS. Curriculum evaluation of ethical reasoning and professional responsibility. J Dent Educ. 2003; 67(1):55-63.

13. fazeli $\mathrm{Z}$, fazeli bavand pour F, rezaee tavirani M, mozafari M, haidari moghadam R. Professional ethics and its role in the medicin . sjimu. 2013; 20 (5) :10-17

14. Abed R. Investigating the Effect of Professional Ethics Indicators on Financial Performance of Companies, Case study: Tehran Stock Exchange. Med J Soc Sci 2016; 7(3 S2), 183.

15. Tripier D. Education of ethic in medical schools. J of pro ethic. 2018;3(2):12-23.

16. Arasteh H, Jahed H. Observing Ethics in Universities and Higher Education Centers: An alternative for improving behaviors. Science Cultivation, 2011; 01(2): 31-40.

17. Valentine S. Human resource management, ethical context, and personnel consequences: A commentary essay. Journal of Business Research. 2010; 63(8):908-10.

18. Bahrani F, Farzin M, Nozari L. Shiraz dentists' knowledge of professional ethics. ijme. 2012; 5 (6) :69-80

19. Tabei S, Azar M, Mahmoodian F, Mohammadi N, Farhadpour H, Ghahramani Y, Al-E-Yasin Z. Investigation of the awareness of the students of shiraz dental school concerning the patients' rights and the principles of ethics in dentistry. J Dent (Shiraz). 2013;14(1):20-4.

20. Karampourian A, Imani B, Torkzaban P. The Attitude of Faculty Members Towards Professional Ethics at Hamadan University School of Dentistry. J Res Dent Sci. 2013;10(1):43-51.

Cite this paper as: Rashidi Maybodi F, Haerian Ardakani A, Khabazzadeh Yazdi M. Ethical Challenges Faced by Senior Dental Students and General Dentists. J Res Dent Maxillofac Sci. 2021; 6 (4):23-29. 